\title{
Changes in cerebral blood flow during anaesthesia and surgery in the sitting position
}

\author{
R J NELSON, A H J LOVICK, J D PICKARD, J BRICE, D SAUNDERS, P J HORSEY \\ From the Wessex Neurological Centre, and Department of Anaesthesia, Southampton General Hospital, \\ Southampton, UK
}

SUMMARY Serial measurements of global cerebral blood flow (CBF) were made in 15 patients undergoing elective neurosurgical procedures in the sitting position, using a modified intravenous 133Xenon technique. ${ }^{1}$ The mean supine CBF rose from $43(+/-3) \mathrm{ml} / 100 \mathrm{~g} / \mathrm{min}$ to $62(+/-6)$ $\mathrm{ml} / 100 \mathrm{~g} / \mathrm{min}$ in the sitting position and remained elevated at the end of surgery at $62(+/-5)$ $\mathrm{ml} / 100 \mathrm{~g} / \mathrm{min}$. Both increases in CBF were statistically significant with respect to baseline supine values.

The threat of cardiovascular instability and air embolism dissuades many neurosurgeons from using the sitting position. ${ }^{2}$ Even in the absence of these complications the cerebral perfusion pressure and cardiac output are known to fall when patients are sat up, and in these circumstances a reduction in CBF might be anticipated. A sustained peroperative fall in CBF could prejudice the outcome of an otherwise uncomplicated procedure. This study was undertaken to examine changes in CBF during anaesthesia and surgery in the sitting position and their relationship, if any, to outcome.

\section{Materials and methods}

The patients studied were undergoing elective surgery under the care of a single consultant neurosurgeon (JB) and two consultant anaesthetists (DS, PJH). Their details; age, sex, preoperative diagnosis, surgical procedure and its duration are shown in table 1 . Seven females and eight males with a mean age of 45 years (range 17-65 years) underwent posterior fossa surgery in 13 cases and cervical surgery in two. The mean duration of anaesthesia was 201 minutes (range 110-390 min). Clinical features of raised intracranial pressure were present in seven of the 15 patients and their CT scans confirmed the presence of significant supratentorial hydrocephalus. None of the patients had serious cardiovascular or respiratory disease although patient 8 was treated with a beta-blocker for essential hypertension.

Address for reprint requests: Professor J D Pickard, Wessex Neurological Centre, Southampton General Hospital, Shirley, Southampton SO9 4XY, UK.

Received 30 September 1986, and in revised form 22 December 1986. Accepted 5 January 1987.
Following premedication with atropine $0.6 \mathrm{mg} \mathrm{IM}$, general anaesthesia was induced using intravenous sodium thiopentone $250-500 \mathrm{mg}$, fentanyl 100-150 $\mu \mathrm{g}$, and alcuronium or pancuronium and maintained with $60 \%$ nitrous oxide/oxygen, fentanyl, alcuronium or pancuronium, supplemented by occasional use of $0.25-0.5 \%$ halothane or $0.2-0.5 \%$ trichloroethylene. In every case the electrocardiogram, radial arterial blood pressure and end tidal pCO2 were continuously monitored (Hewlett Packard; ECG-HP0300A, Pressure transducer-HP1290A, Capnometer-47210A). In 12 cases an oesophageal stethoscope and precordial Doppler probe (Sonicaid Doppler) were employed. A right atrial catheter was inserted in five cases. After endotracheal intubation the patients were mechanically ventilated using a Cape-Wayne Mk111 ventilator, maintaining the end tidal pCO2 between 30 and $35 \mathrm{~mm} \mathrm{Hg}$. Positive and expiratory pressure (PEEP) was added at the discretion of the anaesthetist. All patients had compression bandages applied to their lower limbs and $400-500 \mathrm{ml}$ crystalloid fluid were given intravenously before changing position. A standard neurosurgical chair was used in which the knees were kept flexed to avoid sciatic nerve traction and the head supported in a horseshoe headrest. Rigid cranial fixation was not used.

The global cerebral blood flow was measured using a modified intravenous 133 Xenon technique, deriving the data for cerebral and arterial clearance from single mid-frontal and apical chest probes as previously described from this centre. ${ }^{1}$ After determining the supine control CBF under stable conditions a mean of 27 (range 20-50) minutes following induction of anaesthesia, further measurements were made $13(10-18)$ min after seating the patient, at intervals peroperatively depending on the nature of the procedure and when closing the wound.

The variance of the data was determined and Duncan's Multiple Range Test used to test for statistically significant changes. 
Table 1 Patient details

\section{Results}

The mean supine $\mathrm{CBF}$ rose from $43(+/-3)$ $\mathrm{ml} / 100 \mathrm{~g} / \mathrm{min}$ to $62(+/-6) \mathrm{ml} / 100 \mathrm{~g} / \mathrm{min}$ in the sitting position. The final $\mathrm{CBF}$ remained elevated at 62 $(+/-5) \mathrm{ml} / 100 \mathrm{~g} / \mathrm{min}$. Both increases were statistically significant, $(p<0.05$ and $p<0.01$ respectively). The individual changes in $\mathrm{CBF}$ are shown in table 2.

In a pilot study end-expired and chest clearance of $133 \mathrm{Xe}$ were compared with arterial clearance measured directly by multiple arterial sampling in a patient undergoing a posterior fossa exploration in the sitting position. The clearance curves were well matched, having normalised integrals of $75 \%, 89 \%$ and $100 \%$, indicating chest clearance to be a closer estimate of arterial clearance than end-expired clearance.

In a further three patients the difference between the arterial and end-tidal pCO2 was determined in both the supine and sitting positions by direct arterial blood gas analysis and found to be $4 \cdot 3( \pm 0.5)$ and $1.6( \pm 0.3) \mathrm{mm} \mathrm{Hg}$ respectively

Only two patients suffered an early fall in CBF exceeding $10 \mathrm{ml} / 100 \mathrm{~g} / \mathrm{min}$. In patient No 6 the CBF returned to control values after 50 minutes and the patient made a full recovery. The CBF continued to fall in patient No 11 and at the end of the procedure was $32 \%$ lower than the supine value. She suffered an episode of bradycardia and hypotension during removal of a metastasis adjacent to the medulla. After reversal of anaesthesia she failed to breathe adequately and was ventilated overnight before making a gradual but complete recovery. The final CBF fell by more than $10 \mathrm{ml} / 100 \mathrm{~g} / \mathrm{min}$ in one other patient. During an uneventful cervical laminectomy for extradural tumour, the CBF of patient No 8 fell by $25 \%$. For 72 hours post-operatively he remained unaccountably confused and drowsy.

One perioperative death occurred in this series. Patient 12 underwent removal of a $4 \mathrm{~cm}$ diameter

Table 2 Cerebral blood flow results $\mathrm{ml} / 100 \mathrm{~g} / \mathrm{min}$

\begin{tabular}{|c|c|c|c|c|c|}
\hline No & Supine & Sitting & Closing & $\begin{array}{l}\text { Initial change } \\
\text { (re supine values) }\end{array}$ & $\begin{array}{l}\text { Final } \\
\text { change }\end{array}$ \\
\hline $\begin{array}{l}1 \\
2 \\
3 \\
4 \\
5 \\
6 \\
7 \\
8 \\
9 \\
10 \\
11 \\
12 \\
13 \\
14 \\
15 \\
\text { Mean } \\
\text { SEM } \\
\text { p }\end{array}$ & $\begin{array}{r}33 \\
32 \\
37 \\
34 \\
36 \\
59 \\
57 \\
64 \\
32 \\
35 \\
69 \\
39 \\
47 \\
36 \\
41 \\
43 \\
3\end{array}$ & $\begin{array}{c}50 \\
90 \\
40 \\
43 \\
74 \\
47 \\
75 \\
77 \\
126 \\
33 \\
55 \\
43 \\
60 \\
42 \\
80 \\
62 \\
6 \\
<0.05\end{array}$ & $\begin{array}{c}45 \\
43 \\
30 \\
49 \\
67 \\
100 \\
81 \\
48 \\
53 \\
56 \\
47 \\
66 \\
68 \\
92 \\
85 \\
62 \\
5 \\
<\quad 0.01\end{array}$ & $\begin{array}{l}+17 \\
+58 \\
+3 \\
+9 \\
+38 \\
-12^{*} \\
+18 \\
+13 \\
+94 \\
-2 \\
-14^{*} \\
+4 \\
+13 \\
+6 \\
+39\end{array}$ & $\begin{array}{l}+12 \\
+11 \\
-7 \\
+15 \\
+31 \\
+41 \\
+24 \\
-16^{*} \\
+21 \\
+21 \\
-22^{*} \\
+27 \\
+21 \\
+56 \\
+44\end{array}$ \\
\hline
\end{tabular}

${ }^{*}$ Fall $>10 \mathrm{mls} / 100 \mathrm{~g} / \mathrm{min}$. See text. 
Table 3 Heart rate, $M A P$ and $p C O 2$ results

\begin{tabular}{|c|c|c|c|c|}
\hline & Supine & Sitting & Closing & $p$ \\
\hline $\begin{array}{l}\text { MAP }(\mathrm{mm} \mathrm{Hg}) \\
\text { Heart rate }(\mathrm{bpm}) \\
\text { Pet CO2 }(\mathrm{mm} \mathrm{Hg})\end{array}$ & $\begin{array}{ll}88 \cdot 5(4 \cdot 2) \\
82(4) \\
33 \quad(2)\end{array}$ & $\begin{array}{ll}89 \cdot 5 & (4) \\
81 & (6) \\
31 & (1)\end{array}$ & $\begin{array}{r}115(13) \\
85(5) \\
32 \text { (1) }\end{array}$ & $\begin{array}{l}<0.01 \\
\text { NS } \\
\text { NS }\end{array}$ \\
\hline
\end{tabular}

$(\quad)=$ SEM

acoustic neuroma causing substantial brainstem distortion. In the recovery room she showed signs of a severe pontine disturbance. CT scanning demonstrated a haemorrhagic lesion in the upper pons and midbrain. Throughout the operation her CBFs had risen gradually from 39 to $66 \mathrm{ml} / 100 \mathrm{~g} / \mathrm{min}$. She died on the fifth postoperative day from bronchopneumonia.

Air embolism was detected only once during this study. Twenty minutes after commencing surgery the end tidal pCO 2 of patient No 5 fell suddenly from 33 to $15 \mathrm{~mm} \mathrm{Hg}$ with an accompanying change in the Doppler signal. Although the blood pressure and pulse remained stable the wound was packed and the patient laid flat. After repositioning 10 minutes later the CBF had fallen from an initial sitting value of 74 $\mathrm{ml} / 100 \mathrm{~g} / \mathrm{min}$ to $23 \mathrm{ml} / 100 \mathrm{~g} / \mathrm{min}$. However, the flow improved quickly, reaching $67 \mathrm{ml} / 100 \mathrm{~g} / \mathrm{min}$ before closure, and the patient made an uneventful recovery. In contrast, the operative position of patient No 9 was changed electively. During insertion of cerebellar electrodes the sitting CBF was $83 \mathrm{ml} / 100 \mathrm{~g} / \mathrm{min}$. In the lateral position for insertion of a spinal electrode the CBF fell to $34 \mathrm{ml} / 100 \mathrm{~g} / \mathrm{min}$ (cf supine control CBF 32 $\mathrm{ml} / 100 \mathrm{~g} / \mathrm{min}$ ). After reseating the patient to complete the procedure the CBF rose to $53 \mathrm{ml} / 100 \mathrm{~g} / \mathrm{min}$.

Posterior inferior cerebellar artery aneurysms were clipped in patients No 5 and 14 ten and seven days after their respective subarachnoid haemorrhages. In neither case was any potential impairment of cerebrovascular autoregulation manifested by a fall in CBF.

At the time of the CBF measurement there were no significant changes in heart rate or end tidal pCO2. The mean arterial blood pressure did not change when the patients were first seated but by the end of the surgery had risen from $88 \cdot 5+/-4 \mathrm{~mm} \mathrm{Hg}$ to 115 $+/-3 \mathrm{~mm} \mathrm{Hg}$ (table 3 ). No correlation could be found between the changes in CBF and the patient's age, sex, duration of anaesthesia or presence of raised intracranial pressure.

\section{Discussion}

\section{Cerebral blood flow methodology}

Careful consideration was given to the technique of CBF measurement used in this study. The effect of posture on ventilation perfusion $(\mathrm{Q} / \mathrm{Va})$ ratios $^{3}$ could theoretically have influenced the $133 \mathrm{Xe}$ chest clearance of our patients. In the sitting position apical $\mathrm{Q} / \mathrm{Va}$ falls. Consequently the peak chest counts would be expected to be lower in the sitting than the supine position. However the slope of the chest clearance curve which is dependent on alveolar washout of $133 \mathrm{Xe}$ would not be affected. Since our analysis of the chest clearance curve is independent of peak counts ${ }^{1}$ the potential problem of altered perfusion was excluded. The reliability of chest compared with endtidal and arterial $133 \mathrm{Xe}$ clearance was checked in a pilot patient.

The measurement of end-tidal pCO2 to exclude significant changes in arterial pCO2 has considerable practical advantages over intermittent direct blood gas analysis but certain theoretical considerations are important. A small difference exists between arterial pCO2 and end-tidal pCO2, (a-Et)CO2, owing to the physiological alveolar dead space. In anaesthetised patients Nunn ${ }^{4}$ found this to be a mean of $5 \mathrm{~mm} \mathrm{Hg}$. A change from the supine to sitting position should theoretically increase the dead space and the (a-Et)CO2 difference by increasing basal pulmonary perfusion and altering ventilation perfusion ratios. Although a 2-3 mm Hg increase in the (a-Et)CO2 difference occurs in seated healthy subjects ${ }^{5}$ we found no significant change in the (a-Et)CO2 difference of three ventilated sitting patients which is probably due to a reduction in their basal regional perfusion ${ }^{6}$ and pulmonary shunting. ${ }^{7}$ Thus, having excluded patients with respiratory disease it seems reasonable to use end-tidal PCO2 as a monitor, if not absolute measurement, of arterial $\mathrm{PCO} 2$.

\section{The cerebral circulation and posture}

The cerebral circulation in man depends on an adequate cerebral perfusion pressure (CPP) and the presence of intact cerebral autoregulation. CPP is usually defined as the difference between mean arterial blood pressure (MAP) and intracranial pressure (ICP). In the supine position MAP in the carotid and vertebral circulations, in the absence of arterial disease, is equal to the radial and systemic MAP. But in the erect position common carotid arterial pressure falls by a mean of $20 \mathrm{~mm} \mathrm{Hg}^{8}$ and a further $5-10 \mathrm{~mm} \mathrm{Hg}$ reduction in MAP would be expected in the internal carotid artery entering the cranium. Thus, even with a stable systemic circulation, a seated anaesthetised patient suffers a potential $25 \mathrm{~mm} \mathrm{Hg}$ reduction in CPP. This is partly offset by an accompanying fall in ICP. In normal subjects tilted head up Patterson and Warren measured arterial, internal jugular and cerebrospinal fluid pressures referred to the level of the ear, observing falls of 19.2 and $7.3 \mathrm{~mm} \mathrm{Hg}$ respectively and calculating a $14 \mathrm{~mm} \mathrm{Hg}$ reduction in CPP. ${ }^{9}$ Nornes and Magnaes confirmed that ICP falls in patients under- 
going posterior fossa surgery in the sitting position although they do not comment specifically about CPP. ${ }^{10}$ It is clear that this benefit may be easily lost if poor positioning of the head leads to jugular venous compression. ${ }^{11}$

Relatively few workers have measured the effects of changing posture on $\mathrm{CBF}$. In early studies using a nitrous oxide technique ${ }^{12}$ and continuous oximetric measurement ${ }^{13}$ CBF fell by $20 \%$ when healthy nonfainting subjects were tipped $65 \%$ head up. Normal subjects tolerate these changes easily but elevating the position of patients with cerebrovascular disease may alter the EEG ${ }^{14}$ and result in dramatic clinical deterioration. ${ }^{15}$ In these circumstances it is probable that a global reduction in CBF reduces the effectiveness of collateral circulation to ischaemic tissue. Indirect evidence that CBF would fall in the anaesthetised sitting patient was presented by Tindall et al in $1966 .{ }^{16}$ Using an electromagnetic flow meter they measured internal carotid artery blood flow in nine patients undergoing direct arterial catheterisation for administration of intra-arterial cytotoxic agents. After 9 minutes in the sitting position flow had fallen by an average of $14 \%$.

In contrast to the preceding observations and contrary to our expectations the present study has demonstrated a sustained rise in CBF during anaesthesia and surgery in the sitting position. The reasons for this remain unclear. There is no reason to suspect that changes affecting CPP would differ in our patients from those described above. Since there was no significant early rise in systemic MAP we would predict a fall in MAP at the level of the internal carotid artery of approximately $25 \mathrm{~mm} \mathrm{Hg}$ partly balanced by a reduction in ICP. Although we did not measure ICP there was no difference in the responses of patients with and without evidence of raised ICP and it seems extremely unlikely that ICP would have fallen sufficiently to allow an increase in CBF. We can only attribute the increased CBF to a specific form of autoregulation accompanying the change in posture. In that light it is interesting to note the late increase in MAP of $25.5 \mathrm{~mm} \mathrm{Hg}$ seeming to compensate for the early predicted fall in internal carotid pressure.

A fall in cerebral blood flow which was not related directly to surgical trauma to the brain stem occurred only twice. The only morbidity which might be attributed to such a fall was a period of postoperative confusion. Despite the apparent resilience of the cerebral circulation suggested by these observations it would be foolish to assume that an increase in global CBF measured supratentorially assures an adequate circulation to the brainstem. One might equally argue that the increased CBF and MAP are the direct responses of a brainstem struggling with inadequate perfusion. However, in only two of our cases were there clinical signs of brainstem dysfunction and in each case they were directly attrributable to surgical manoeuvres.

The average duration of our procedures was 3 hours 20 minutes and the final CBF was measured 20-30 minutes before reversal of anaesthesia. Only one CBF measurement was made after more than 4 hours of surgery. Whether CBF would start to deteriorate during more lengthy procedures remains unknown.

\section{Conclusions}

This study has shown that elevation of anaesthetised patients to the sitting position is followed by an early and sustained rise in CBF, and a delayed rise in MAP. In selected patients free of serious cardio-respiratory or cerebrovascular disease the use of the sitting position does not appear to affect adversely the cerebral circulation.

This paper was presented at the Cambridge meeting of the British Society of Neurological Surgeons in March 1986.

Funded in part by the Chest, Heart and Stroke Association.

\section{References}

1 Pickard JD, Read DH, Lovick AHJ. In: Hartmann A, Hoyer S, eds. Cerebral Blood Flow and Metabolism Measurements. New York: Springer Verlag, 1985: 149-52.

2 Standefer M, Bay JW, Trusso R. The sitting position in neurosurgery: a retrospective analysis of 488 cases. Neurosurgery 1984;6:649-58.

3 Amis TC, Jones HA, Hughes JMB. Effect of posture on inter-regional distribution of pulmonary perfusion and $\mathrm{Va} / \mathrm{Q}$ ratios in man. Respir Physiol 1984;56: $169-82$.

4 Nunn JF, Hill DW. Respiratory dead space and arterial to end-tidal $\mathrm{Co} 2$ tension difference in anesthetized man. J Appl Physiol 1960;15(3):383-9.

5 Larson CP Jr, Severinghaus JW. Postural variations in dead space and $\mathrm{CO} 2$ gradients breating air and $\mathrm{O} 2$. $J$ Appl Physiol 1962;17(3):417-20.

6 Landmark SJ, Knopp TJ, Rehder K, Sessler AD. Regional pulmonary perfusion and $\mathrm{V} / \mathrm{Q}$ in awake and anesthetised and paralysed man. J Appl Physiol 1977;43(6):993-1000.

7 Dalrymple DG, MacGowen SW, MacLeod GF. Cardiorespiratory effects of the sitting position in neurosurgery. Br J Anaesth 1979;51:1079-81.

8 Loman J, Dameshek W, Myerson A, Goldman D. Effect on alterations in posture on the intra-arterial blood pressure in man. 1. Pressure in the varotid, brachial, and femoral arteries in normal subjects. Arch Neurol Psych 1936;35:1216-24. 
9 Patterson JL Jr, Warren JV. Mechanism of adjustment in the cerebral circulation upon assumption of the upright position. J Clin Invest 1952;31:653.

10 Nornes H, Magnaes B. Supratentorial epidural pressure recorded during posterior fossa surgery. J Neurosurgery 1971;35:541-9.

11 Hulme A, Cooper R. The effects of head position and jugular vein compression (JVC) on intracranial pressure (ICP). A clinical study. In: Beks JFW, Bosch DA, Brook M, eds. Intracranial Pressure III. Berlin: Springer-Verlag, 1976:259-63.

12 Scheinberg P, Stead EA Jr. The cerebral blood flow in male subjects as measured by the nitrous oxide technique. Normal values for blood flow, oxygen utilisation, glucose utilisation, and peripheral resistance, with observations on the effect of tilting and anxiety. $J$ Clin Invest 1949;28:1163-71.

13 Patterson JL Jr, Canon JI. Postural changes in the cerebral circulation, studied by continuous oximetric and pressure-recording techniques. J Clin Invest 1951;30: 664.

14 Meyer JS, Leiderman H, Denny-Brown D. Electroencephalographic study of insufficiency of the basilar and carotid arteries in man. Neurology 1956;6:455-77.

15 Caplan LR, Sergay S. Positional cerebral ischaemia. J Neurol Neurosurg Psychiatry 1976;39:385-91.

16 Tindall GT, Craddock A, Greenfield JC Jr. Effects of the sitting position on blood flow in the internal carotid artery of man during general anaesthesia. $J$ Neurosurgery 1967;26:383-9. 